\title{
'Keep an open mind': using qualitative research to make recruitment easier in the by-band randomised controlled trial
}

\author{
Sangeetha Paramasivan ${ }^{1 *}$, Chris Rogers², Graziella Mazza², Jane Blazeby', Jenny Donovan¹, By-Band TMG ${ }^{1,2}$ \\ From 2nd Clinical Trials Methodology Conference: Methodology Matters \\ Edinburgh, UK. 18-19 November 2013
}

\section{Background}

Surgical randomised controlled trials (RCTs) are acknowledged to be particularly challenging to conduct and recruit to. Within a programme of research to understand and optimise recruitment to RCTs, we undertook qualitative research in the By-Band RCT (comparison of gastric bypass and gastric band operations for morbid obesity).

\section{Methods}

In Phase I, challenges to recruitment were explored through thematic analysis of a) interviews with trial staff and recruiters and b) audio-recordings and observations of recruitment appointments. In Phase II, anonymised findings presented to recruiters in group and individual feedback sessions led to changes in information provision and logistical aspects of recruitment.

\section{Results}

In Phase I, interview data revealed recruiters' varying levels of equipoise and preferences, and patient pathway charting identified complex clinical arrangements. Audio-recordings and observations of recruitment appointments highlighted five key challenges to recruitment: a) there was little discussion of By-Band b) By-Band was not well integrated into the clinical service c) eligibility assessment was unclear d) patient preferences were accepted at face value and e) information provision was not tailored to the patient. In Phase II, suggestions to recruiters included integrating the RCT within current service provision, streamlining eligibility assessment, exploring patient preferences, providing balanced and tailored information, and requesting

School of Social and Community Medicine, University of Bristol, Bristol, UK Full list of author information is available at the end of the article patients to keep an open mind throughout the appointment. Recruitment rates increased from $4 \%$ prior to feedback to $30 \%$ and $64 \%$ in the two months following feedback. Research is on-going to further optimise recruitment.

\section{Conclusion}

Qualitative research methods are well placed to optimise recruitment rates in surgical RCTs.

\section{Authors' details}

${ }^{1}$ School of Social and Community Medicine, University of Bristol, Bristol, UK ${ }^{2}$ School of Clinical Sciences, Clinical Trials and Evaluation Unit, University of Bristol, Bristol, UK

Published: 29 November 2013

doi:10.1186/1745-6215-14-S1-054

Cite this article as: Paramasivan et al:: 'Keep an open mind': using qualitative research to make recruitment easier in the by-band randomised controlled trial. Trials 2013 14(Suppl 1):O54.

Submit your next manuscript to BioMed Central and take full advantage of:

- Convenient online submission

- Thorough peer review

- No space constraints or color figure charges

- Immediate publication on acceptance

- Inclusion in PubMed, CAS, Scopus and Google Scholar

- Research which is freely available for redistribution 